\title{
NOTES
}

\section{World System for Abstracting and Indexing}

Columbus, Ohio-The International Council of Scientific Unions Abstracting Board (ICSU $A B \backslash$ at its annual meeting here agreed to go ahead with a plan for the first stage of a world system for abstracting and indexing services for science and technology.

The Abstracting Board's members include eleven of the world's major abstracting and indexing services from France, Germany, U.S.A., U.S.S.R., and United Kingdom.

The first stage plan defines guidelines for cooperation among the member services of the Abstracting Board in the acquisition, selection, and exchange of documents for coverage by the services. It is aimed primarily at eliminating much of the duplication in journal acquisition that exists among the world's principal abstracting and indexing services.

Under the plan, the member services from each scientific discipline would assume the responsibility for acquiring and selecting articles for coverage from the most productive journals in their discipline. Articles in these journals that are of potential interest to other disciplines would be forwarded in microform, along with the author abstract and a standard computer-readable bibliographic description, to the appropriate other services, either directly or through a central redistributing unit. Responsibility for acquiring and selecting articles for coverage from a substantial number of journals that are primarily devoted to scientific fields outside of those covered by the member services will be allocated among the member services according to the languages of the journals, with articles of potential interest routed to the appropriate services for coverage.

The design, implementation, and operation of a world system for abstracting and indexing services are primary long-range goals of the ICSU Abstracting Board, Board President Dr. Byron Riegel said. Cooperation among the member services in journal acquisition and document selection is a first important step toward this goal.

Such cooperation would substantially reduce the costs of document acquisition and selection for each of the member services and for the world scientific abstracting and indexing complex as a whole, Dr. Riegel pointed out. Each of the member services will have to acquire and process far fewer journals. While services covering the same discipline in different languages will each continue to acquire the core journals of that discipline, they will no longer need to acquire a substantial number of journals devoted primarily to other disciplines.

The arrangement also will contribute importantly to the completeness of coverage of the abstracting services in each of the disciplines, Dr. Riegel said. Each service in effect will be able to draw information from the aggregate journal coverage of the member services, which is estimated to be about 35,000 journals.

The first steps toward implementing the plan will be agreement upon common definitions of subject coverage, selection procedures, and forms for bibliographic citations among the member services, and studies of the degree of overlap that now exists in the journals abstracted by the member services. The plan also calls for a detailed inventory of the computerreadable records produced by the various member services to identify the degree of compatibility and convertability among these records and analysis of the indexing approaches used by member services with the ultimate aim of the direct exchange of abstracts and index entries among the services. The member services of the ICSU Abstracting Board are Astronomy and Astrophysics Abstracts, Bibliographie des Sciences de la Terre, Bibliography and Index of Geology, BioSciences Information Service of Biological Abstracts, Bulletin Signalétique, Chemical Abstracts Service, Chemischer Informationsdienst, Science Abstracts, Physikalische Berichte, Referativnyi Zhurnal, and Zentralblatt für Mathematik.

The Proceedings of the July 1970 meeting of the ICSU Abstracting Board, which include the description of the first stage of the plan for a world system for abstracting and indexing services, are available at the ICSU Abstracting Board Secretariat, 17 rue Mirabeau, Paris $16 \mathrm{e}$, France. (U.S. $\$ 15.00$ plus mailing charges.) 